Article

\title{
The Collective Strategies of Key Stakeholders in Sponge City Construction: A Tripartite Game Analysis of Governments, Developers, and Consumers
}

\author{
Yan Chen ${ }^{1,2, *}$ and Hongmei Chen ${ }^{1}(\mathbb{D}$ \\ 1 College of Economics and Management, Nanjing Forestry University, Nanjing 210037, China; \\ honmy_c@njfu.edu.cn \\ 2 Research Institute of Ecological Civilization Construction and Forestry Development with Chinese \\ Characteristics, Nanjing Forestry University, Nanjing 210037, China \\ * Correspondence: sanchen007@njfu.edu.cn; Tel.: +86-025-8542-7377
}

Received: 24 February 2020; Accepted: 9 April 2020; Published: 11 April 2020

\begin{abstract}
In the early stage of sponge city promotion, both developers and consumers lack initiative, and the governments can take incentive measures to encourage both groups to actively participate in the construction of sponge city. This paper makes a comparative analysis of the interest composition and obstacles faced by the three key stakeholders: governments, developers, and consumers, and establishes an asymmetric evolutionary game model of governments, developers, and consumers. The dynamic system of the game model is constructed by replicated dynamic equation, and the evolution direction of different stages is obtained by solving the stable equilibrium point of the system. Based on the reasonable assumption of the parameter value, the numerical simulation is carried out for the situation of oversupply, short supply, and balance of supply and demand. The results show that the better evolutionary equilibrium points are (incentive, development, purchase) and (no incentive, development, purchase). The basic factors influencing the decision-making direction of the stakeholder are direct cost, direct benefit, opportunity cost, and opportunity benefit. In a fixed scenario, the decision-making direction is unchanged, and the parameters can change the evolution speed of the whole system, which can reduce the loss or accelerate the promotion. Moreover, some suggestions are put forward for the governments, developers, and consumers in the construction of sponge city.
\end{abstract}

Keywords: sponge city; evolutionary game; decision-making behavior; numerical simulation

\section{Introduction}

According to the investigation data of the Ministry of Housing and Urban-Rural Development on the rain and flood disasters in 351 cities in China, $60 \%$ of the cities have experienced waterlogging, the depth of which is generally more than $15 \mathrm{~cm}$ and the time is more than $30 \mathrm{~min}$, which has brought great inconvenience to the travel and life of urban residents, caused huge economic losses, and even restricted the development of the city. Therefore, the goal of building a sponge city is proposed in China. Since 2014, with the promotion of the Ministry of Housing and Urban-Rural Development of the People's Republic of China, many cities have started to build sponge projects and formulated the construction objectives of corresponding technical standards. There are more than a thousand pilot projects nationwide so far, with an average construction area of $30.8 \mathrm{~km}^{2} \mathrm{~s}$ [1], which involves the reconstruction of old communities, the construction of new communities, river management, and the reconstruction of public facilities. 
Sponge city is an important urban planning direction in response to the frequent occurrence of urban rain and flood disasters in China and has a positive role in alleviating the heat island effect, water resource shortage, and building the urban water ecological security pattern [2]. The construction concept is to make the whole urban system like a sponge to absorb and reuse rainwater resources at the right time. Figure 1 shows the concept of the overall operation of the sponge city. During the rainfall, some of the rainwater can be recycled and stored. Sponge projects with a filtering effect can simply purify the collected rainwater. When people need water, filtered rainwater can be reused. Sponge city is usually equipped with rainwater recovery system, green roof, rainwater garden, sunken square, permeable pavement, etc. Green roof can slow down urban heat island effect, and permeable pavement can reduce surface runoff and waterlogging. Sponge city planning and design in China mostly draw lessons from low impact development in the United States [3,4], water sensitive urban design in Australia, and sustainable urban drainage system in the United Kingdom [5,6]. However, due to the vast territory and complex terrain of China, the design of each region needs to be adapted to local conditions, and the planning objectives are also different. Under the overall planning of the central government, local governments need to make further plans to adapt to local planning and design. In addition to the 30 national sponge city pilot cities selected by the Ministry of Housing and Urban-Rural Development have more subsidies [7], many projects still need to be funded by local governments, which is a huge expenditure for local governments. However, the direct economic loss caused by the lack of active control of the rain and flood disaster is between US \$15-22 million [8]. Sponge city is a major project related to the overall planning of the city, in which the government can only play a leading role. The specific construction is related to the decision-making of the construction developer. Whether consumers are willing to pay additional costs for the sponge project will affect the overall construction of the sponge city project in the region.

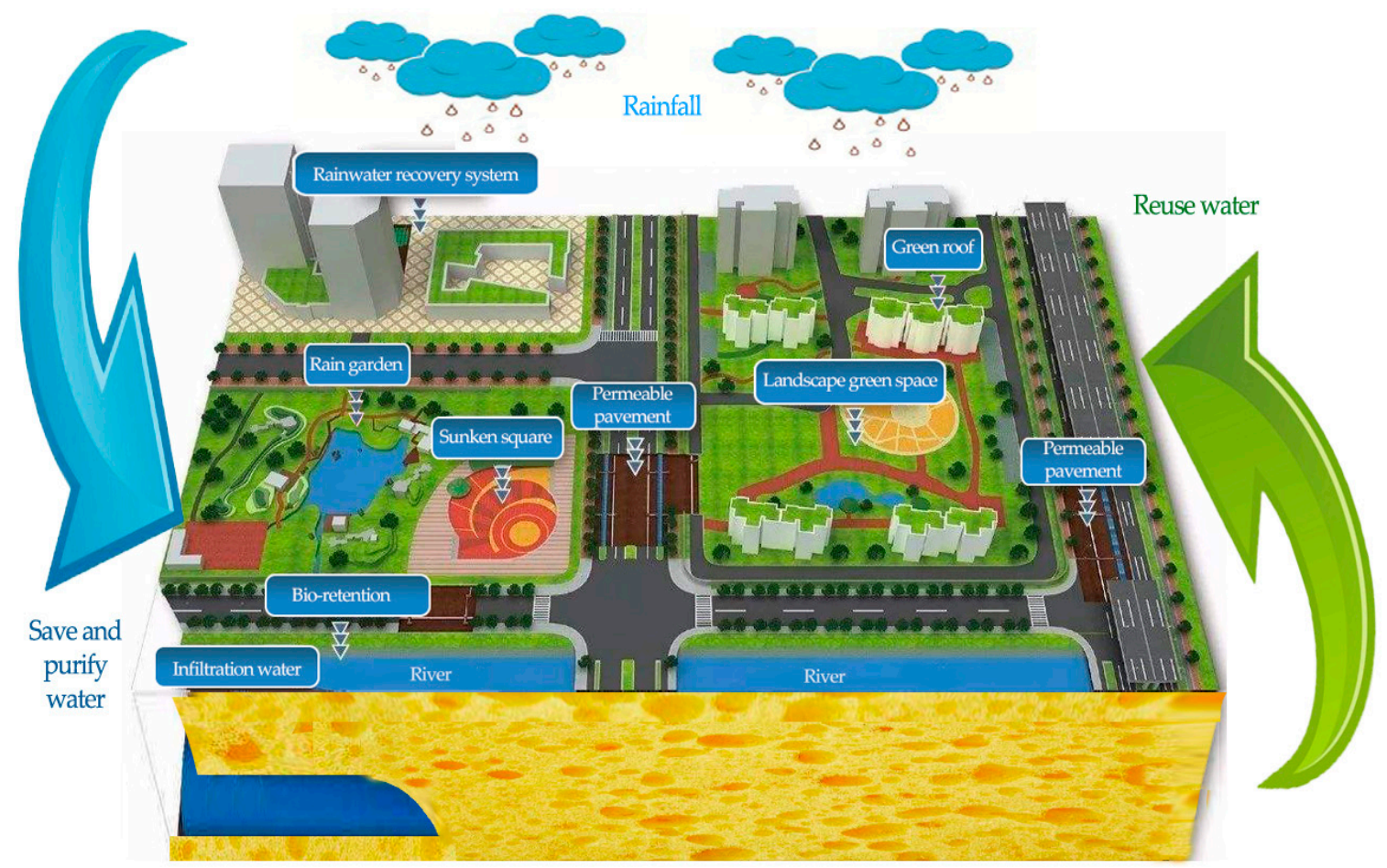

Figure 1. Sketch of sponge city.

The study of sponge city can be divided into three parts: planning and design, measurement and evaluation, and scheme improvement. The planning part can be traced back to people's attention to urban rainwater management $[9,10]$. Many scholars analyzed the problems faced by different regions and made targeted suggestions [11]. This part focused on the problems and solutions until 
the Ministry of Housing and Urban-Rural Development of People's Republic of China issued the technical guide for sponge city construction: construction of low-impact development rainwater system in 2014 [12]. After putting forward the goals of total amount control, peak value control, pollution control, and rainwater resource utilization, scholars began to pay attention to the problems and solutions in the construction of sponge cities $[7,13]$ and proposed planning solutions for specific areas [14]. Smaller scales include residential areas, parks, schools, etc. $[15,16]$. Larger scales take a characteristic city as the research object [17]. Part of the planning is mostly based on the guideline [12]. According to the characteristics of the research object, some requirements have been added, such as landscape pleasantness, biodiversity, and ecological water cycle [18]. In the measurement evaluation section, we mainly take the sponge project that has been built in the current period as an example. The ecological, social, and economic benefits of the construction project are considered, and the appropriate evaluation index system is designed to evaluate the low-impact development facilities [19]. The rainwater management capacity of different low-impact development facilities under the situation was simulated $[20,21]$. The construction risk of the sponge city construction project was evaluated by the grey fuzzy intuition analytic hierarchy process [22]. China still has a certain gap in technology, research methods, and evaluation systems compared with developed countries [23]. In the improvement part of the program, people are not satisfied with drawing on other countries and begin to adjust according to local conditions [24]. In the hilly areas of southern China, the runoff target decomposition design is carried out, the rainwater superimposed features of the upper-middle and lower reaches are considered, and the design of "rainwater feedback" is added. This means that the calculation of "rainwater superposition" is added in the planning process according to the activity tracking of rainwater. In this way, it is more accurate to select suitable low-impact development facilities at different elevations. In the existing context, explore the combination ratio of different facilities to better achieve the goal of runoff control $[25,26]$.

Most of the research on the stakeholders of sponge city still stays at the level of government supervision [27], and with the rise of the sponge community, developers and consumers have gradually become key stakeholders. The existing research mainly explores the application of Public-Private Partnership model in the construction of sponge city and the problems that may arise [28]. From the perspective of public management, the governments and consumers pay for the sponge city to solve the problem of income [29]. In this context, developers and consumers lack the autonomy to choose and can only passively accept policies. Existing research ignores its autonomy as a key stakeholder and reflects on government policies [30]. Different positions of stakeholders have been found through economic and financial analysis of sponge city projects. From the perspective of the government, sponge city should be promoted, while for the project builders, from the perspective of financial analysis, the construction of sponge city projects would lose money [31].

Evolutionary game applies to the case of finite rationality of the object of study and can reach finite equilibrium state through learning and imitation. At present, it is widely used in the research of green supply chain, new energy vehicles, green home appliances market, green buildings, and other fields of environmental protection and energy conservation [32]. Some scholars use evolutionary game to study the collective strategies of the central government, local land administration, and land expropriated farmers in land expropriation [33]. This method can also be used to capture dynamically the interactive behavior of strategy selections based on building information modeling (BIM) [34]. It is also combined with the system dynamics to carry out the game and simulation research on the evolution of the quadripartite safety supervision system for high-speed railway companies and their agents [35]. Evolutionary game theory in all walks of life the economy played an important role in social studies. In the context of building a sponge city, the decision-making role of developers and consumers and the game analysis of developers and the government, consumers and the government is considered. Some scholars have established an evolutionary game to study how the government regulates developers to promote sponge city construction at the building and community scale [36]. 
Although some scholars realize that it is not enough to only study the government's measures to promote the construction of sponge city, there are still little research involving the perspective of developers and consumers at present, especially the demand-side perspective, and little literature involves the participation of consumers in the final recommendations. In the multi-participation scenario, the decision-making of the stakeholder is dynamic, and the current research on the relevant aspects is also insufficient. This paper analyzes the interaction among the three key stakeholders: governments, developers, and consumers, and constructs a tripartite evolutionary game model. According to the dynamic replication equation of the three main bodies, the game dynamic system is established, the stable equilibrium point of the decision dynamic system is obtained, and the evolution direction of the three-party decision-making groups in different construction stages is discussed. Using MATLAB software to carry out numerical simulation under different scenarios, we analyzed the sensitivity of influencing factors and put forward suggestions for the construction and promotion of sponge city.

\section{Analysis of the Interactions of Key Stakeholders}

\subsection{Governments}

For local governments, if urban stormwater management cannot be reasonably managed, urban traffic, people's security, and related economic losses will hinder the development of the city. In China, there are many cities with rainy summer and frequent waterlogging disasters. There is a great risk for the safety of pedestrians on the road. In the bad traffic environment, there is no condition for timely treatment, and the safety of life cannot be guaranteed. The long time and high frequency of urban road ponding reduce the service cycle and increase maintenance times. At the same time, rainstorm impacts subway, light rail, and other urban traffic. For the government, the cost of infrastructure maintenance caused by rainstorm damage every year is a large expenditure.

In the early stage of sponge city construction, the government needs to act as a guide, formulate relevant technical standards, prepare construction guidance, invest funds to build or transform pilot projects, and conduct acceptance evaluation after the completion of construction. During the pilot period, the public welfare nature of the project is mainly considered. The key task is to build parks, urban roads, affordable housing, and other kinds of non-profit projects. The technology mainly focuses on Low-Impact Development and Green Infrastructure. The main acceptance standard is the ability of rainwater regulation and control and certain esthetics of the project.

\subsection{Developers}

When the developer develops the project, the main decision-making basis is the final benefit. Under normal circumstances, the cost of sponge project construction is higher than that of ordinary projects, and it is necessary to contact new raw material suppliers to learn new technologies and new planning and design. The extra cost will inevitably lead to price increases, and whether consumers pay attention to the environmental benefits brought by the sponge project determines whether the developer can make a profit. Without knowing the market demand, the developer does not dare to try to innovate.

The government's incentives can encourage developers to develop sponge projects. When the government subsidies and management fees exceed the developer's additional costs, developers will choose to develop sponge projects. To promote more consumers to purchase sponge projects, developers can give a discount on the price. The quantity usually sold will also be affected by the price of a single set of transactions. When consumers have a large demand for sponge projects, the government does not need incentives, and developers will also develop sponge projects. 


\subsection{Consumers}

When consumers purchase real estate, they usually pay more attention to the location, appreciation space, and so on. However, according to the consumer mental accounting theory, consumers have improved their ecological awareness, paying more attention to the living environment [37], and have a tendency to purchase sponge projects, which can increase the weight of the "sponge" elements in each consideration. In the initial stage of construction, in order to promote consumers to prioritize sponge projects, they can levy certain environmental management fees for owners of other types of industries and promote the concept of sponge city, so that consumers can obtain a certain percentage of preferential treatment when purchasing sponge projects. The above measures can change the purchasing tendency of consumers.

In order to promote a virtuous cycle of developer construction and consumer purchase, the most important thing is to effectively improve the quality of the construction of the sponge project, so that the owners can feel the improvement of the living environment brought by the sponge project, and the owners' property fee payment rate is high. It is beneficial to provide economic support for the maintenance of sponge project. Focusing on the owner's environmental awareness and quality improvement of project construction, consumers will feel more value for money and will be more willing to purchase sponge projects.

\subsection{Interactions}

In the construction of sponge city, the interests of government, developers, and consumers are mutually affected. Figure 2 shows the interactions among the three stakeholders. The government motivates developers' construction enthusiasm and consumers' purchase enthusiasm through the incentive system. The quality of developers' construction directly affects the city's development benefits and consumers' residential benefits. The purchase and maintenance rate of consumers affects the developer's operating income and the city's development benefits. The government's revenue comes from the taxation of developers and consumers, the investment attracted by the construction of the sponge city, and the development benefits of the sponge project after construction. The expenditure includes the management costs of the relevant departments of the sponge city and subsidies to developers and consumers. The developer's income includes sales income and government subsidies, and the expenditure includes development costs and taxes paid. Consumer benefits include housing benefits and government subsidies, and costs include purchase and maintenance costs and taxes paid. However, these parameters do not appear in every scenario.

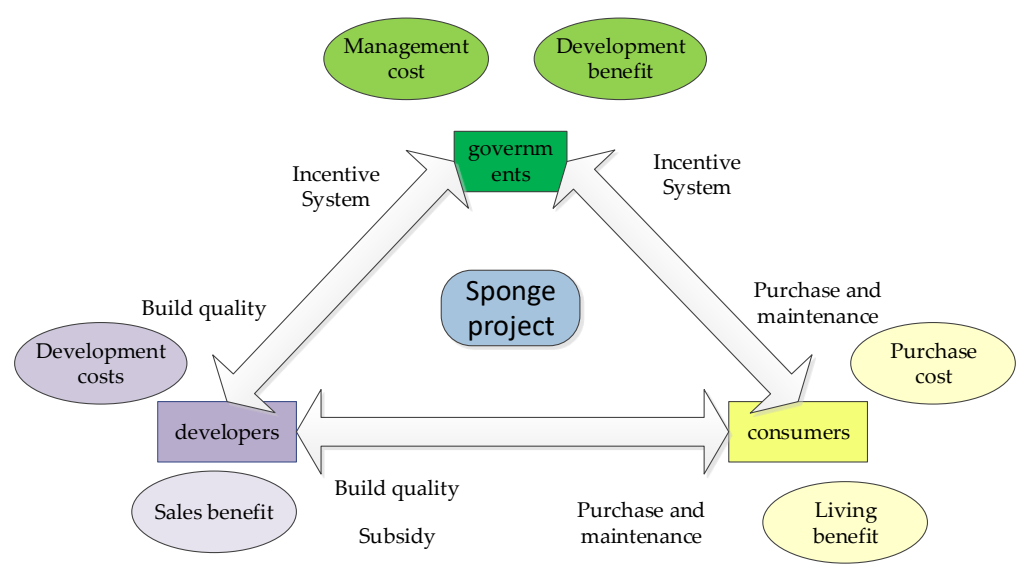

Figure 2. Interaction among government, developers, and consumers.

In the early stage of sponge city construction, the government can benefit most from it. However, both developers and consumers lack the incentive to participate. This paper studies the promotion stage of sponge city construction. It will take a long time for the effect of the construction quality of 
developers and the impact of purchase and maintenance of consumers to be reflected. Therefore, when selecting elements in the model, the most important intermediate elements, that is, the elements directly related to the two parties, have two aspects. One is the government's incentive system for developers and consumers, that is, taxes and subsidies. The other is the degree of price concessions offered by developers to attract consumers to buy sponge projects. In addition to the two intermediate elements, complete modeling also needs to consider the peripheral elements involved in each stakeholder, that is, the elements directly related to only one party, usually their respective direct costs and direct benefits. Different choices made by the stakeholder will produce different results, and the choice of each stakeholder will affect the other two parties, which will be discussed in the next part.

\section{Tripartite Evolutionary Game Model in Sponge City Construction}

Based on the analysis of the interest relationship between the key stakeholders in the foregoing, reasonable assumptions are made according to the actual situation, an evolutionary game model between the three is established, and the payment matrix of the model is obtained. Then, we calculated the expected return function and replicated the dynamic equation of the government, developer, and consumer, and then built a three-dimensional dynamic system of the model. We performed stability analysis to get the overall evolution direction of the model under different circumstances.

\subsection{Symbol Descriptions}

The strategic space of government departments is (incentive, no incentive), and the proportion is $x$ and $1-x$, respectively. Incentive includes positive incentive subsidy and negative incentive taxation. The decision-making space of the developer is (development, no development), and the proportion is $y$ and 1-y, respectively. The "no development" represents other projects developed by the developer. The decision-making space of consumers is (purchase, no purchase), and the proportion is $z$ and 1-z, respectively. No purchase represents that consumers purchase other non-sponge projects.

The government implements the incentive strategy, with the fixed expenditure cost of $C_{1}$ and the subsidy to developers of $S$. The fixed cost mainly refers to the publicity and management expenses. Once the incentive policy is implemented, it will become the fixed expenditure, regardless of whether the developers choose the development strategy or not. Different from the subsidy, the subsidy is only issued when the developers choose the development. The tax on undeveloped enterprises is $T_{1}$, and the tax on consumers who do not purchase is $T_{2}$. If the developer chooses to develop, the development benefit obtained by the government is $W_{1}$. After the successful construction of the sponge project, it can effectively control the runoff, reduce the road area water, and prevent and control the waterlogging. Sponge city can play the role of urban rainwater and flood management. In addition, the utilization of rainwater resources can increase the total amount of available water resources. The purification systems can improve water quality. Green roof helps to slow down the heat island effect. It improves the overall infrastructure function of the city. If the developer does not build, the cost of disaster recovery by the government is $C_{2}$. Because the developer does not build sponge project, this area may suffer casualties, damage to public facilities, and other losses due to rainstorm weather. The government needs to treat the injured and repair the public facilities, which will cost public resources and economic costs. When the government decided to encourage the construction of sponge projects, it will attract external investment, which is recorded as $W_{4}$. This part of investment comes from the special funds appropriated by the higher authorities, as well as the funds from other individuals or groups excluding the government.

When developers develop sponge projects, the extra cost is $C_{3}$. If the government adopts incentive strategy at this time, the developers will get subsidy $S$. In order to attract consumers to purchase the developed projects, a certain proportion of subsidy will be given to the consumers who purchase sponge projects, which is recorded as a, a as the subsidy proportion. After consumers purchase sponge projects, the developers will get additional income of $W_{2}$. Under the condition of government incentive, 
the development of other projects instead of sponge projects needs to pay certain urban construction tax, which is recorded as $T_{1}$.

The extra cost for consumers to purchase sponge projects is $C_{4}$, while compared with other non-sponge cities, the extra revenue is $W_{3}$. Under the condition of government incentive, the purchase of sponge project will get the preferential benefit from the developer, which is a s, while the non-purchase of sponge project needs to pay a certain urban management tax, which is recorded as $T_{2}$. When the developer is undeveloped and the consumer has the purchase intention, there is no need to pay taxes, waiting for other enterprises to develop and purchase, but the consumer does not purchase sponge projects; however, when he purchases other projects, he needs to pay taxes.

Table 1 shows the parameters in the model, their corresponding meanings, and parameter attributes.

Table 1. Parameter definitions.

\begin{tabular}{|c|c|c|}
\hline Parameter Symbol & Descriptions & Parameter Attribute \\
\hline$a$ & Preferential ratio of developers to consumers & intermediate element \\
\hline$a S$ & Benefits for consumers & intermediate element \\
\hline$C_{1}$ & Government promotion, management fees & peripheral element \\
\hline$C_{2}$ & Government disaster recovery, facility maintenance, direct loss & peripheral element \\
\hline$C_{3}$ & The additional cost of the developer building a sponge project & peripheral element \\
\hline$C_{4}$ & The additional cost for consumers to purchase sponge items & peripheral element \\
\hline$S$ & Government subsidies to developers of sponge projects & intermediate element \\
\hline$T_{1}$ & $\begin{array}{c}\text { A tax levied by the government on developers who build } \\
\text { non-sponge projects }\end{array}$ & intermediate element \\
\hline$T_{2}$ & $\begin{array}{c}\text { A tax imposed by the government on consumers who purchase } \\
\text { non-sponges }\end{array}$ & intermediate element \\
\hline$W_{1}$ & $\begin{array}{c}\text { Urban development benefits obtained by the government } \\
\text { building sponge project }\end{array}$ & peripheral element \\
\hline$W_{2}$ & $\begin{array}{l}\text { Additional operating income of developers developing } \\
\text { sponge projects }\end{array}$ & peripheral element \\
\hline$W_{3}$ & $\begin{array}{c}\text { Consumers' purchase of sponge project gains increased living } \\
\text { environment benefits }\end{array}$ & peripheral element \\
\hline$W_{4}$ & $\begin{array}{l}\text { Government's other income (social investment) from } \\
\text { incentive policy }\end{array}$ & peripheral element \\
\hline$x$ & Government incentive ratio & decision ratio \\
\hline$y$ & Developer development ratio & decision ratio \\
\hline$z$ & Consumer purchase ratio & decision ratio \\
\hline
\end{tabular}

The stakeholders of this paper are bounded rationality, have certain learning ability, and finally reach the optimal state in many studies. The decision of the three stakeholders is sequential. Figure 3 shows a periodic game process. It should be noted that, when the developer is not developing, the consumer can still choose to wait for development instead of purchasing other properties. At this time, the consumer is selected to purchase the strategy.

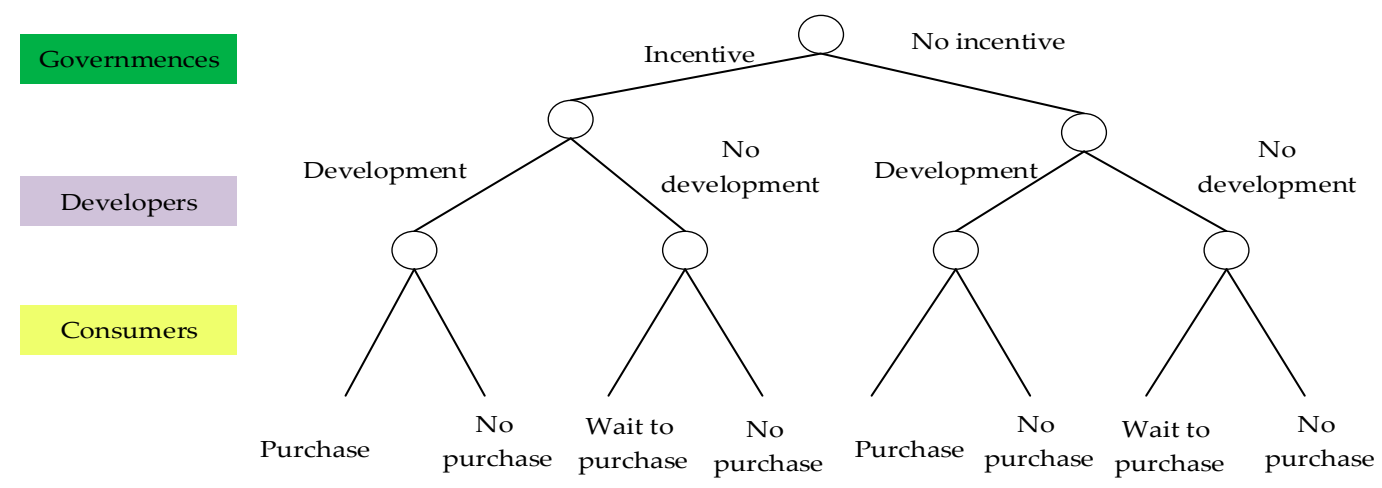

Figure 3. Game tree. 
Based on the above assumptions, a three-party game model is established to calculate the benefits of each key stakeholder under different decisions. Table 2 is the income matrix of this game model. From the top to the bottom of each line are the revenue of the government, developers, and consumers.

Table 2. The payment matrix of the game model of governments, developers, and consumers.

\begin{tabular}{cccc}
\hline & & Consumers (Purchase) & Consumers (No Purchase) \\
\hline \multirow{3}{*}{$\begin{array}{c}\text { Governments } \\
\text { (incentive) }\end{array}$} & Developers & $W_{1}-C_{1}-S+W_{4}$ & $W_{1}-C_{1}+W_{4}-S+T_{2}$ \\
& (development) & $W_{2}-C_{3}+(1-a) S$ & $S-C_{3}$ \\
& & $a S+W_{3}-C_{4}$ & $-T_{2}$ \\
\cline { 2 - 4 } & Developers & $T_{1}+W_{4}-C_{1}-C_{2}$ & $T_{1}+T_{2}-C_{1}+W_{4}-C_{2}$ \\
& (no development) & $-T_{1}$ & $-T_{1}$ \\
Governments & Developers & 0 & $-T_{2}$ \\
\hline (no incentive) & (development) & $W_{1}$ & $W_{1}$ \\
\cline { 2 - 4 } & & $W_{2}-C_{3}$ & $-C_{3}$ \\
& Developers & $W_{3}-C_{4}$ & 0 \\
\hline & (no development) & $-C_{2}$ & $-C_{2}$ \\
& & 0 & 0 \\
\hline
\end{tabular}

\subsection{Replicated Dynamic Equation}

According to evolutionary game theory, in the group composed of limited rational players, the strategy with better results than the average level will gradually be adopted by more players, so the proportion of players who adopt various strategies in the group will change. Replicated dynamic equation is a dynamic differential equation or a system of differential equations used to express this dynamic phenomenon.

When the government chooses incentives, it should consider the four scenarios (incentive, development, purchase), (incentive, development, no purchase), (incentive, no development, purchase), and (incentive, no development, no purchase) and the corresponding probability when calculating the expected revenue. Equation (1) shows the calculation process.

When the government chooses no incentive, the calculation of its expected return should consider the return and corresponding probability of four scenarios (no incentive, development, purchase), (no incentive, development, no purchase), (no incentive, no development, purchase), and (no incentive, no development, no purchase). Equation (2) shows the calculation process.

The average expected revenue is the sum of the expected revenue of each government strategy multiplied by the corresponding probability. The revenue of incentive strategy is higher than the average expected revenue. When calculating the government's replication dynamic equation, it is the product of the probability of the incentive strategy multiplied by the difference between the expected revenue and the average expected revenue of the government's incentive strategy. Equation (3) shows the calculation process.

The replicated dynamic equation of developers and consumers can be solved in the same way.

The expected revenue of the government's choice of incentive strategy is $u_{11}$, and the expected revenue of no incentive is $u_{12}$, as follows:

$$
\begin{gathered}
u_{11}=y z\left(W_{1}-C_{1}+W_{4}-S\right)+y(1-z)\left(W_{1}-C_{1}+W_{4}-S+T_{2}\right)+(1-y) z\left(T_{1}+W_{4}-C_{1}-C_{2}\right)+(1-y)(1-z)\left(T_{1}+T_{2}+W_{4}-C_{1}-C_{2}\right) \\
u_{12}=y z W_{1}+y(1-z) W_{1}+(1-y) z\left(-C_{2}\right)+(1-y)(1-z)\left(-C_{2}\right)
\end{gathered}
$$

The average expected revenue can be calculated by the formula $U_{1}=x \times u_{11}+(1-x) u_{12}$. The replicated dynamics equation for governments can be achieved as follows:

$$
F(x)=d x / d t=x\left[u_{11}-\left(x \times u_{11}+(1-x) u_{12}\right)\right]=x(1-x)\left(u_{11}-u_{12}\right)=x(x-1)\left(C_{1}-W_{4}-T_{1}-T_{2}+S y+T_{1} y+T_{2} z\right)
$$


The expected revenue of the developer choosing the development strategy is $u_{21}$, and the expected revenue of the developer choosing not to develop is $u_{22}$, as follows:

$$
\begin{gathered}
u_{21}=x z\left[W_{2}-C_{3}+(1-a) S\right]+x(1-z)\left(S-C_{3}\right)+(1-x) z\left(W_{2}-C_{3}\right)+(1-x)(1-z)\left(-C_{3}\right) \\
u_{22}=x z\left(-T_{1}\right)+x(1-z)\left(-T_{1}\right)
\end{gathered}
$$

The average expected revenue for developers are computed by $U_{2}=y \times u_{21}+(1-y) u_{22}$. Then, the replicated dynamics equation for developers can be achieved as follows:

$$
G(y)=d y / d t=y(1-y)\left(S x-C_{3}+T_{1} x+W_{2} z-S a x z\right)
$$

The expected revenue of adopting "Purchase" and "No purchase" strategies can be obtained by:

$$
\begin{gathered}
u_{31}=x y\left(a S+W_{3} C_{4}\right)+(1-x) y\left(W_{3}-C_{4}\right) \\
u_{32}=x y\left(-T_{2}\right)+x(1-y)\left(-T_{2}\right)
\end{gathered}
$$

The average expected revenue for consumers are computed by $U_{2}=z \times u_{31}+(1-z) u_{32}$. Then, the replicated dynamics equation for consumers can be achieved as follows:

$$
H(z)=d z / d t=z(1-z)\left(T_{2} x-C_{4} y+W_{3} y+S a x y\right)
$$

The dynamics of evolution equations of the expropriation system can be obtained from the combination of Equations (3), (6), and (9):

$$
\left\{\begin{array}{c}
F(x)=\frac{d x}{d t}=x \times(x-1) \times\left(C_{1}-W_{4}-T_{1}-T_{2}+S \times y+T_{1} \times y+T_{2} \times z\right) \\
G(y)=\frac{d y}{d t}=y \times(1-y) \times\left(S \times x-C_{3}+T_{1} \times x+W_{2} \times z-S \times a \times x \times z\right) \\
H(z)=\frac{d z}{d t}=z \times(1-z) \times\left(T_{2} \times x-C_{4} \times y+W_{3} \times y+S \times a \times x \times y\right)
\end{array}\right.
$$

\subsection{Stability Analysis}

Eight equilibrium points can be obtained by solving the equations, namely the boundary of the evolutionary game, which are $E_{1}(0,0,0), E_{2}(1,0,0), E_{3}(0,1,0), E_{4}(0,0,1), E_{5}(1,1,0), E_{6}(1,0,1), E_{7}(0,1,1)$ and $E_{8}(1,1,1)$. The stability of the equilibrium point can be obtained through the Jacobian matrix expansion analysis. The Jacobian matrix of the system is as follows:

$$
\left[\begin{array}{ccc}
(2 x-1) \times\left(\begin{array}{c}
C_{1}-W_{4}-T_{1}-T_{2}+ \\
S \times y+T_{1} \times y+T_{2} \times z
\end{array}\right) & x \times(x-1) \times\left(S+T_{1}\right) & x \times(x-1) \times T_{2} \\
y \times(1-y) \times\left(S+T_{1}-S \times a \times x \times z\right) & (1-2 y) \times\left(\begin{array}{c}
S \times x-C_{3}+T_{1} \times x+ \\
W_{2} \times z-S \times a \times x \times z
\end{array}\right) & y \times(1-y) \times\left(W_{2}-S \times a \times x\right) \\
z \times(1-z) \times\left(T_{2}+S \times a \times y\right) & z \times(1-z) \times\left(C_{4}+W_{3}+S \times a \times x\right) & (1-2 z) \times\left(\begin{array}{c}
T_{2} \times x-C_{4} \times y+ \\
W_{3} \times y+S \times a \times x \times y
\end{array}\right)
\end{array}\right]
$$

The stability of the equilibrium point is mainly determined by the sign of the eigenvalue. When the three eigenvalues of the corresponding Jacobian matrix are all less than 0 , the equilibrium point is the stable equilibrium strategy point. The 8 equilibrium points and corresponding eigenvalues of the system are shown in Table 3. The stable equilibrium point of the system cannot be distinguished under the uncertainty of the specific value. 
Table 3. The system equilibrium points and their eigenvalues.

\begin{tabular}{|c|c|c|c|c|}
\hline \multirow{2}{*}{ Equilibrium Points } & \multicolumn{3}{|c|}{ Eigenvalues } & \multirow{2}{*}{$\begin{array}{l}\text { Stability or Stability } \\
\text { Conditions }\end{array}$} \\
\hline & $\lambda_{1}$ & $\lambda_{2}$ & $\lambda_{3}$ & \\
\hline$E_{1}(0,0,0)$ & $T_{1}+T_{2}-C_{1}+W_{4}$ & $-C_{3}$ & 0 & Unstable \\
\hline$E_{2}(1,0,0)$ & $C_{1}-T_{1}-T_{2}-W_{4}$ & $S-C_{3}-T_{1}$ & $T_{2}$ & Unstable \\
\hline$E_{3}(0,1,0)$ & $T_{2}-C_{1}-S-W_{4}$ & $C_{2}$ & $-C_{4}$ & Unstable \\
\hline$E_{4}(0,0,1)$ & $T_{1}-C_{1}-W_{4}$ & $W_{2}-C_{3}$ & 0 & Unstable \\
\hline$E_{5}(1,1,0)$ & $C_{1}-T_{2}+S-W_{4}$ & $C_{3}-S-T_{1}$ & $T_{2}+W_{3}-C_{4}+a S$ & $\lambda 1<0, \lambda 2<0, \lambda 3<0$ \\
\hline$E_{6}(1,0,1)$ & $C_{1}-T_{1}-W_{4}$ & $S+T_{1}-C_{3}+W_{2}-a S$ & $-T_{2}$ & $\lambda 1<0, \lambda 2<0, \lambda 3<0$ \\
\hline$E_{7}(0,1,1)$ & $-C_{1}-S+W_{4}$ & $C_{3}-W_{2}$ & $C_{4}-W_{3}$ & $\lambda 1<0, \lambda 2<0, \lambda 3<0$ \\
\hline$E_{8}(1,1,1)$ & $C_{1}+S-W_{4}$ & $C_{3}+a S-S-T_{1}-W_{2}$ & $C_{4}-T_{2}-W_{3}-a S$ & $\lambda 1<0, \lambda 2<0, \lambda 3<0$ \\
\hline
\end{tabular}

For $E_{1}(0,0,0)$, the eigenvalue $\lambda_{3}=0, E_{1}$ is unstable. For $E_{2}(1,0,0)$, the eigenvalue $\lambda_{3}=T_{2}>0, E_{2}$ is unstable. Similarly, $E_{3}(0,1,0)$ and $E_{4}(0,0,1)$ are unstable.

For $E_{5}(1,1,0)$, the sponge project market is characterized by oversupply, $C_{1}-T_{2}+S-W_{4}<0, C_{3}-$ $S-T_{1}<0, T_{2}+W_{3}-C_{4}+a S<0 . E_{5}$ is a stable equilibrium point. At this point, it is necessary for the government to impose an urban management tax on consumption and attract external investment that exceeds the fixed cost of management publicity and subsidies to developers. The additional cost of developers is less than the sum of subsidies and taxes given by the government, but the extra cost of sponge project for consumers is on the high side.

For $E_{6}(1,0,1)$, the sponge project market is in short supply. $C_{1}-T_{1}-W_{4}<0, S+T_{1}-C_{3}+W_{2}$ $-a S<0, E_{6}$ is the stable equilibrium point. The government can afford the relevant expenditure of incentive decision through tax and fund-raising. Consumers have a large demand for sponge projects, but developers lack the motivation for development.

For $E_{7}(0,1,1)$, the sponge project achieves the coordination of supply and demand without government incentives. $-C_{1}-S+W_{4}<0, C_{3}<W_{2}, C_{4}<W_{3}, E_{7}$ has become a stable equilibrium point of the system, that is, the market spontaneously forms the situation that developers develop sponge projects and consumers purchase sponge projects without incentives from the government.

For $E_{8}(1,1,1)$, the sponge project market shows a balance of supply and demand, which is an ideal equilibrium evolution point. $C_{1}+s-W_{4}<0, C_{3}+a S-S-T_{1}-W_{2}<0, C_{4}-T_{2}-W_{3}-a S<0$, the government needs to maintain the implementation of incentive policies through social fund-raising, developers actively develop sponge projects under the government's incentive, and consumers actively purchase sponge projects under the government's incentive and developer's incentive.

We need to classify the elements with each stakeholder. For the government, $C_{1}$ and $S$ are the direct costs, $T_{1}, T_{2}$, and $W_{4}$ are the direct benefits. For developers, $C_{3}$ and $a S$ are direct costs, $S$ and $W_{2}$ are direct benefits, and $T_{1}$ is opportunity benefit. For consumers, $C_{4}$ is direct cost, $a S$ and $W_{3}$ are direct benefits, and $T_{2}$ is opportunity benefit. Although the opportunity cost is not listed, it can still be inferred that when direct benefit + opportunity benefit $>$ direct cost + opportunity cost, the stakeholder tends to participate in the construction of sponge city and otherwise tends not to participate.

\section{Numerical Simulation}

According to the results of stability analysis, four scenarios of sponge city construction can be obtained from four equilibrium points. The data of one sample is not good for numerical simulation of multiple scenarios. In addition, some parameters involved in this paper lack quantitative analysis standards and data, so it is appropriate to select hypothesis data. According to the relevant data in the existing quantitative analysis [31], some parameters of the government and enterprises are calculated by referring to their proportions. For consumer-related and other parameters that are difficult to quantify, assumptions are made in accordance with economic principles and reality. Moreover, the adjustment of different parameters is tried to study the law of model evolution speed.

The two-dimensional pictures more clearly reflect the change of the decision ratio over time, and all the verification of quantitative to qualitative conclusions is based on this. Based on these, solutions to specific problems can be found. Three-dimensional pictures are more spatial. They show that 
the change in the model is holistic. They imply the mutual influence among the three main bodies. Relatively few curves contain complete information. They more intuitively reflect the overall evolution trend. Comparing two-dimensional and three-dimensional images, from the perspective of reaching the equilibrium point of evolution as soon as possible, the model is not completely consistent with each stakeholder.

\subsection{Oversupply Scenario Simulation}

According to the results of the previous stability analysis, the scenario of oversupply is simulated. First, the parameters are reasonably assumed to satisfy the condition of $E_{5} . C_{1}-T_{2}+S-W_{4}<0, C_{3}-$ $S-T_{1}<0, T_{2}+W_{3}-C_{4}+a S<0$. The specific settings are as shown in scenario A1 in Table 4 , and other values are appropriately adjusted to obtain the sensitivity of the parameter. Scenario A2 reduces $x$ by 0.1 , scenario A3 reduces $a$ by 0.1 , and scenario A4 reduces $y$ by 0.1 . Iteration is repeated once every $0.01 \mathrm{~s}$ for a total of 500 iterations. Figure 4 shows the simulation results oversupply scenario.

Table 4. Value of oversupply scenario.

\begin{tabular}{ccccc}
\hline $\begin{array}{c}\text { Parameter } \\
\text { Symbol }\end{array}$ & $\begin{array}{c}\text { Scenario A1 } \\
\text { (Black) }\end{array}$ & Scenario A2 (Red) & Scenario A3 (Blue) & $\begin{array}{c}\text { Scenario A4 } \\
\text { (Green) }\end{array}$ \\
\hline$a$ & 0.2 & 0.2 & {$[0.1]$} & 0.2 \\
$C_{1}$ & 5 & 5 & 5 & 5 \\
$C_{2}$ & 20 & 20 & 20 & 20 \\
$C_{3}$ & 10 & 10 & 10 & 10 \\
$C_{4}$ & 12 & 12 & 12 & 12 \\
$S$ & 5 & 5 & 5 & 5 \\
$T_{1}$ & 6 & 6 & 6 & 6 \\
$T_{2}$ & 5 & 5 & 5 & 5 \\
$W_{1}$ & 10 & 10 & 10 & 6 \\
$W_{2}$ & 6 & 6 & 6 & 3 \\
$W_{3}$ & 3 & 3 & 3 & 6 \\
$W_{4}$ & 6 & 6 & 6 & 0.2 \\
$x$ & 0.2 & {$[0.1]$} & 0.2 & {$[0.1]$} \\
$y$ & 0.2 & 0.2 & 0.2 & 0.2 \\
\hline
\end{tabular}

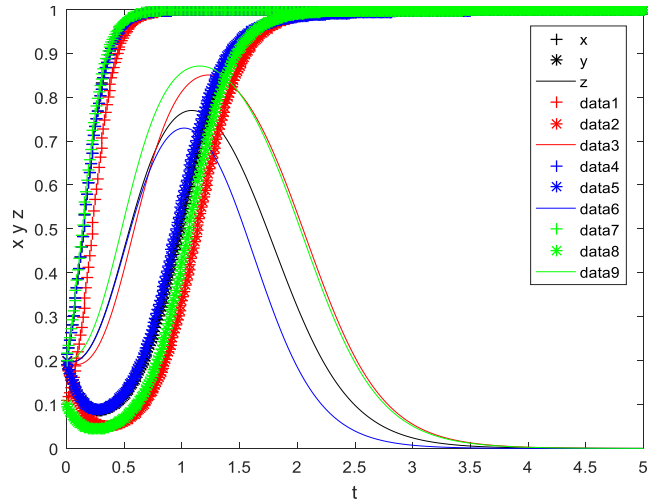

(a)

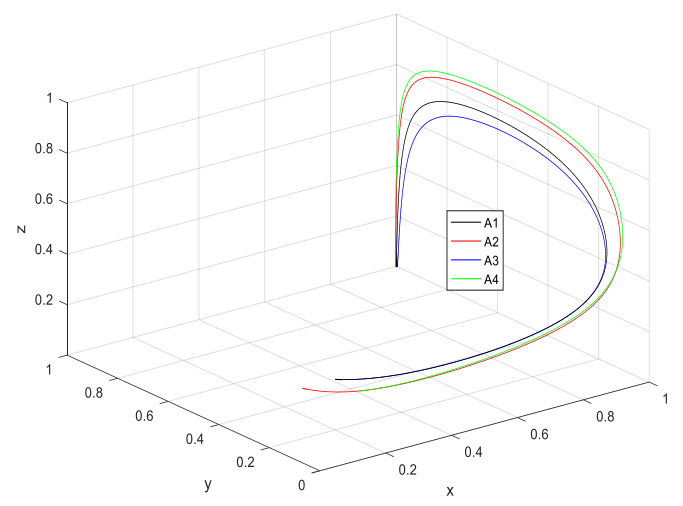

(b)

Figure 4. System evolution trend chart of oversupply scenario. (a) Two-dimensional evolution diagram, (b) Three-dimensional evolution diagram.

According to the results of the simulation, scenario A4 best meets expectations. However, the speed at which the stakeholders reach the equilibrium point is not the same. When the perceived benefit of the consumer is much lower than the comprehensive cost of purchasing the sponge project $\left(C_{4}\right.$ is much higher than $\left.W_{4}\right)$, some consumers will purchase sponge projects in the early stage because 
of the freshness or high expectations. However, as the number of users choosing purchasing strategies increases, consumers gradually have a more unified evaluation of the sponge project. Other consumers will choose not to buy a sponge project when they realize that the benefits are lower than the costs. Moreover, at this time, the government's influence on incentives for consumer decision-making is temporary, and the government can only promote consumers to purchase sponge projects in the short term by raising taxes. The evolution results will not change without changing external conditions such as acquisition costs. Therefore, in the scenario of oversupply, developers need to appropriately reduce the development speed and increase the proportion of concessions, promote more consumers to purchase sponge projects, and actively seek breakthroughs to improve the living efficiency of consumers. Without excessively increasing the burden on consumers, the government can appropriately increase the amount of tax to prevent consumer groups from evolving in the direction of non-purchase.

\subsection{Short Supply Scenario Simulation}

When simulating the supply shortage scenario, it is necessary to assume that the parameters satisfy $C_{1}-T_{1}-W_{4}<0, S+T_{1}-C_{3}+W_{2}-a S<0$, and the specific settings are shown in Table 5 . By adjusting other parameters, the parameter sensitivity is obtained. Scenario B2 reduces $x$ by 0.1 , scenario B3 reduces $y$ by 0.1 , scenario B4 reduces $z$ by 0.1 , and scenario B5 adjusts $S$ to 10 , every 0.05 -s iteration; 1 time, a total of 100 iterations. Figure 5 shows the numerical simulation results of short supply scenario.

Table 5. Value of short supply scenario.

\begin{tabular}{cccccc}
\hline $\begin{array}{c}\text { Parameter } \\
\text { Symbol }\end{array}$ & $\begin{array}{c}\text { Scenario B1 } \\
\text { (Black) }\end{array}$ & $\begin{array}{c}\text { Scenario B2 } \\
\text { (Red) }\end{array}$ & $\begin{array}{c}\text { Scenario B3 } \\
\text { (Blue) }\end{array}$ & $\begin{array}{c}\text { Scenario B4 } \\
\text { (Green) }\end{array}$ & $\begin{array}{c}\text { Scenario B5 } \\
\text { (Magenta) }\end{array}$ \\
\hline$a$ & 0.2 & 0.2 & 0.2 & 0.2 & 0.2 \\
$C_{1}$ & 5 & 5 & 5 & 5 & 5 \\
$C_{2}$ & 20 & 20 & 20 & 20 & 20 \\
$C_{3}$ & 10 & 10 & 10 & 10 & 10 \\
$C_{4}$ & 12 & 12 & 12 & 12 & 12 \\
$S$ & 5 & 5 & 5 & 5 & {$[10]$} \\
$T_{1}$ & 2 & 2 & 2 & 2 & 2 \\
$T_{2}$ & 5 & 5 & 5 & 5 & 5 \\
$W_{1}$ & 10 & 10 & 10 & 10 & 10 \\
$W_{2}$ & 3 & 3 & 3 & 3 & 3 \\
$W_{3}$ & 3 & 3 & 3 & 3 & 3 \\
$W_{4}$ & 4 & 4 & 4 & 4 & 4 \\
$x$ & 0.2 & {$[0.1]$} & 0.2 & 0.2 & 0.2 \\
$y$ & 0.2 & 0.2 & {$[0.1]$} & 0.2 & 0.2 \\
$z$ & 0.2 & 0.2 & 0.2 & {$[0.1]$} & 0.2 \\
\hline
\end{tabular}

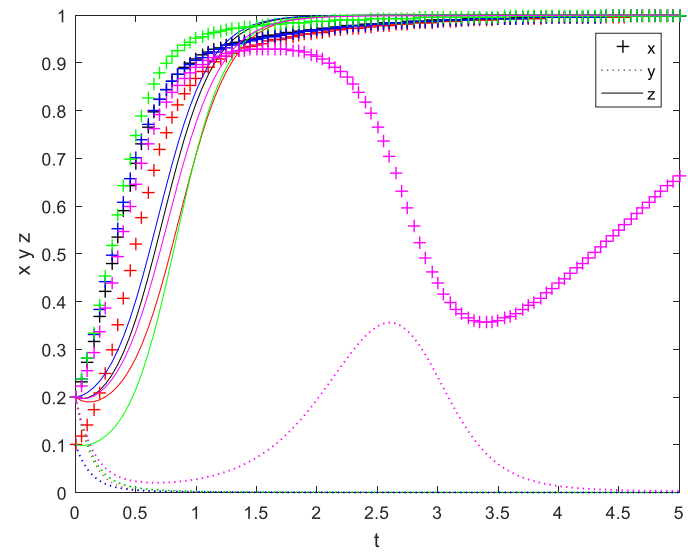

(a)

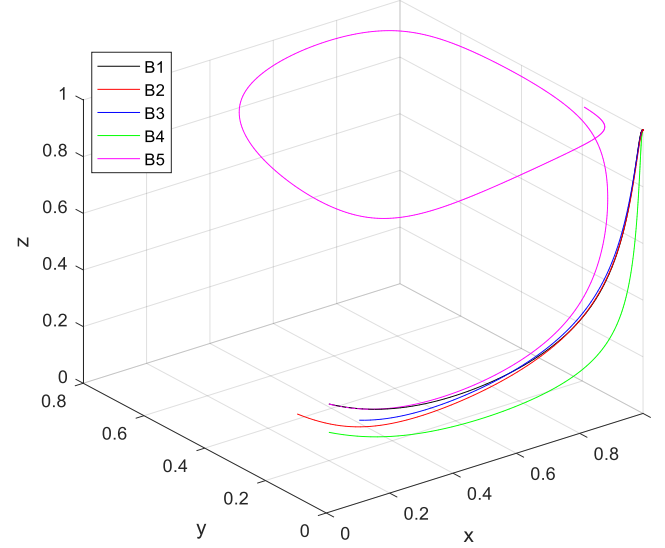

(b)

Figure 5. Evolution trend chart of oversupply scenario. (a) Two-dimensional evolution diagram, (b) Three-dimensional evolution diagram. 
According to the results of the simulation, when the developer's sales revenue is too low, the group will not choose to continue to develop the sponge project. The government can use the subsidy to some extent to promote the development of the sponge project, but the proportion of development is never high. It shows that when the developer lacks development motive, the government has limited incentives. In order to change the overall development of the sponge project, the government can encourage sponge technology innovation and reduce the developer's construction cost indirectly, thereby improving the developer's development power. The proportion of development has an impact on the proportion of consumer purchases and government incentives. It is necessary to calculate the specific value of the adjustment based on the results of the evolution analysis carefully.

\subsection{Supply and Demand Coordination Scenario Simulation}

According to the above analysis, there are two situations in the coordination of supply and demand, and they are discussed separately.

First, we discuss the scenario of $E_{8}$. $E_{8}$ is the supply and demand coordination scenario under government incentives. The parameters are assumed to satisfy $C_{1}+S-W_{4}<0, C_{3}+a S-S-T_{1}-W_{2}$ $<0, C_{4}-T_{2}-W_{3}-a S<0$, the specific settings are shown in Table 6 , and other parameters are adjusted to get different scenarios, scenario $C_{2}$ will reduce $x$ by 0.1 , scenario $C_{3}$ will decrease $y$ by 0.1 , scenario $C_{4}$ will reduce $z$ by 0.1 , and scenario $C 5$ will adjust the value of $a$ to 0.1 , iterating once every 0.05 s, a total of 100 iterations. Figure 6 shows the numerical simulation results of supply and demand coordination scenario.

Table 6. Value of supply and demand coordination scenario.

\begin{tabular}{cccccc}
\hline $\begin{array}{c}\text { Parameter } \\
\text { Symbol }\end{array}$ & $\begin{array}{c}\text { Scenario } \\
\text { C1 (Black) }\end{array}$ & $\begin{array}{c}\text { Scenario } \\
\text { C2 (Red) }\end{array}$ & $\begin{array}{c}\text { Scenario } \\
\text { C3 (Blue) }\end{array}$ & $\begin{array}{c}\text { Scenario } \\
\text { C4 (Green) }\end{array}$ & $\begin{array}{c}\text { Scenario C5 } \\
\text { (Magenta) }\end{array}$ \\
\hline$a$ & 0.2 & 0.2 & 0.2 & 0.2 & {$[0.1]$} \\
$C_{1}$ & 3 & 3 & 3 & 3 & 3 \\
$C_{2}$ & 20 & 20 & 20 & 20 & 20 \\
$C_{3}$ & 10 & 10 & 10 & 10 & 10 \\
$C_{4}$ & 12 & 12 & 12 & 12 & 12 \\
$S$ & 5 & 5 & 5 & 5 & 5 \\
$T_{1}$ & 6 & 6 & 6 & 6 & 6 \\
$T_{2}$ & 5 & 5 & 5 & 5 & 5 \\
$W_{1}$ & 10 & 10 & 10 & 10 & 10 \\
$W_{2}$ & 6 & 6 & 6 & 6 & 6 \\
$W_{3}$ & 7 & 7 & 7 & 7 & 7 \\
$W_{4}$ & 9 & 9 & 9 & 9 & 9 \\
$x$ & 0.2 & {$[0.1]$} & 0.2 & 0.2 & 0.2 \\
$y$ & 0.2 & 0.2 & {$[0.1]$} & 0.2 & 0.2 \\
$z$ & 0.2 & 0.2 & 0.2 & {$[0.1]$} & 0.2 \\
\hline
\end{tabular}

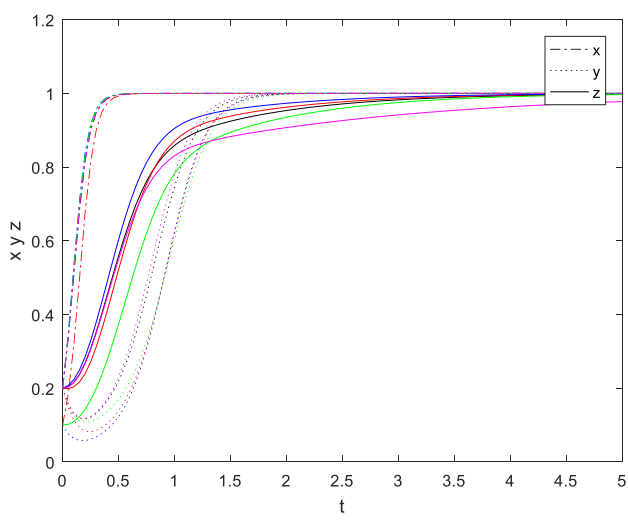

(a)

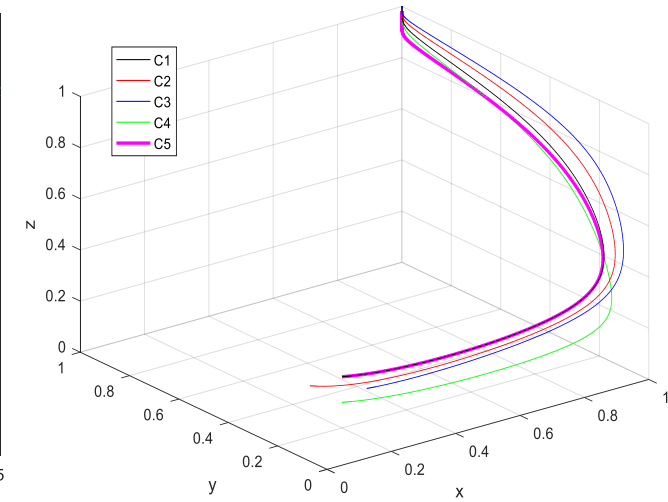

(b)

Figure 6. System evolution trend chart of supply and demand coordination scenario. (a) Twodimensional evolution diagram, (b) Three-dimensional evolution diagram. 
According to the results of the simulation, scenario C3 reaches the evolutionary stability point fastest. When the government's management costs and subsidy expenditures are less than the benefits of implementing incentive policies, the government will always choose to encourage the development of sponge projects. Under the conditions of government incentives, when developers' development costs and preferential quotas are less than the sum of sales revenue, government subsidy income, and negative incentives (taxes), developers always choose to develop sponge projects. Similarly, under government incentives, consumers will always purchase a sponge project when the cost of purchasing a sponge project is less than the sum of the benefits they receive, the benefits of living, and the tax revenue as an opportunity. If and only if the three conditions are established at the same time, the situation of government incentives, developer development, and consumer purchase will be formed. In the short run, the three stakeholders are pursuing their own interests, but in terms of long-term development, the interests of the three are mutually influential, and the three should take the initiative to look at the construction and promotion of the sponge project from a comprehensive perspective.

Finally, the $E_{7}$ scenario is discussed. $E_{7}$ is the supply and demand coordination scenario under anarchic incentive. The parameters are assumed to satisfy $-C_{1}-S+W_{4}<0, C_{3}<W_{2}, C_{4}<W_{3}$, and the parameters are adjusted. The specific settings are shown in Table 7. Scenario D2 will reduce $x$ by 0.1 , scenario D3 will decrease $y$ by 0.1 , scenario D4 will reduce $z$ by 0.1 , and scenario D 5 will adjust $a$ to 0.1 , iterating once every $0.05 \mathrm{~s}$, a total of 200 iterations. Figure 7 shows the numerical simulation results of ideal scenario.

Table 7. Value of ideal scenario.

\begin{tabular}{cccccc}
\hline $\begin{array}{c}\text { Parameter } \\
\text { Symbol }\end{array}$ & $\begin{array}{c}\text { Scenario } \\
\text { A1 (Black) }\end{array}$ & $\begin{array}{c}\text { Scenario } \\
\text { A2 (Red) }\end{array}$ & $\begin{array}{c}\text { Scenario } \\
\text { A3 (Blue) }\end{array}$ & $\begin{array}{c}\text { Scenario } \\
\text { A4 (Green) }\end{array}$ & $\begin{array}{c}\text { Scenario B5 } \\
\text { (Magenta) }\end{array}$ \\
\hline$a$ & 0.2 & 0.2 & 0.2 & 0.2 & {$[0.1]$} \\
$C_{1}$ & 5 & 5 & 5 & 5 & 5 \\
$C_{2}$ & 20 & 20 & 20 & 20 & 20 \\
$C_{3}$ & 5 & 5 & 5 & 5 & 5 \\
$C_{4}$ & 6 & 6 & 6 & 6 & 6 \\
$S$ & 5 & 5 & 5 & 5 & 5 \\
$T_{1}$ & 6 & 6 & 6 & 6 & 6 \\
$T_{2}$ & 5 & 5 & 5 & 5 & 5 \\
$W_{1}$ & 10 & 10 & 10 & 10 & 10 \\
$W_{2}$ & 6 & 6 & 6 & 6 & 6 \\
$W_{3}$ & 7 & 7 & 7 & 7 & 7 \\
$W_{4}$ & 9 & 9 & 9 & 9 & 9 \\
$x$ & 0.2 & {$[0.1]$} & 0.2 & 0.2 & 0.2 \\
$y$ & 0.2 & 0.2 & {$[0.1]$} & 0.2 & 0.2 \\
$z$ & 0.2 & 0.2 & 0.2 & {$[0.1]$} & 0.2 \\
\hline
\end{tabular}

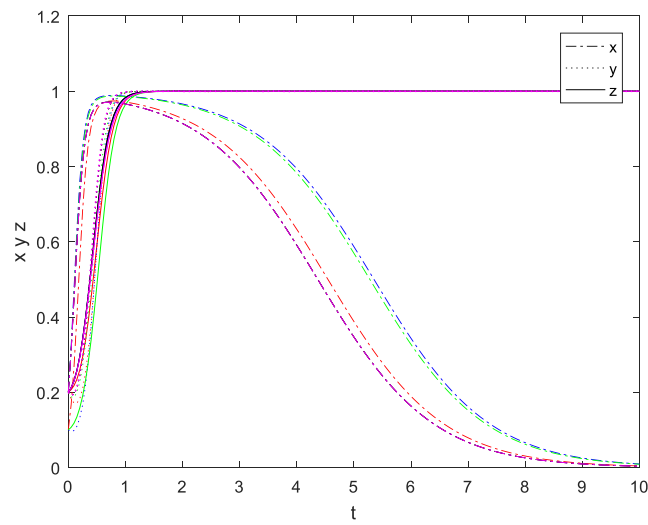

(a)

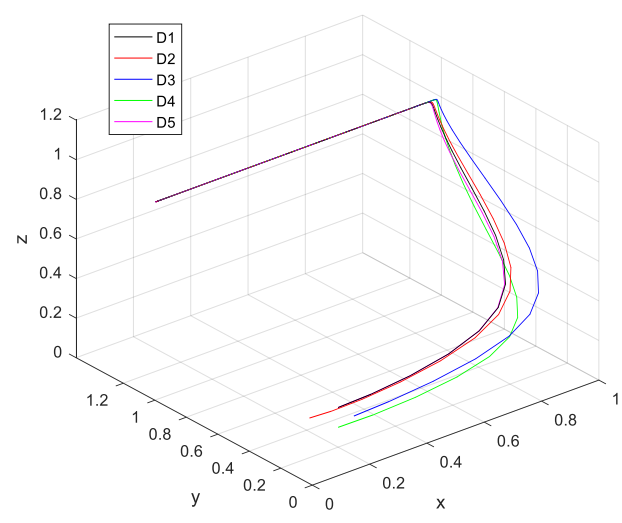

(b)

Figure 7. System evolution trend chart of ideal scenario. (a) Two-dimensional evolution diagram, (b) Three-dimensional evolution diagram. 
According to the evolutionary results of Figure 7, the system can always evolve to the equilibrium point of (no incentive, development, purchase) when the eigenvalues are less than 0 . The incentive proportion of the government continues to rise until the developers consciously develop and the consumers spontaneously purchase. The incentive proportion of the government gradually decreases and finally evolves to the state of no incentive, which is the state of sponge city development to the mature stage. The developer's construction cost is low, and the benefits from the development of the sponge project are enough to stimulate the developer to develop. The maturity of technology improves the construction effect. Consumers value the living environment. When purchasing sponge projects, the benefits in their psychological accounts are higher than the costs. So, they are willing to purchase sponge projects without other incentives. At this time, the government should consider the regulatory issues, guarantee the development quality of the sponge project, prevent the purchasing power of consumers from being reduced due to quality problems, and guide the overall development of the sponge city.

\section{Conclusions and Discussion}

In this paper, the evolutionary game model is established to analyze the interaction among the government, developers, and consumers in the construction of sponge city. Different scenarios of oversupply, short supply, and coordination of supply and demand in the construction of sponge city are put forward. Based on these studies, some conclusions are drawn and some discussions are conducted on the high-quality construction of sponge city:

First, the equilibrium strategy state point of each agent cannot exist alone, which is affected by the strategies of the other two parties. The optimal decision-making of the stakeholder will change with time and other stakeholders' strategies. The better evolutionary equilibrium state of the tripartite game model established in this paper is (incentive, development, purchase) and (no incentive, development, purchase). Among them, (incentive, development, purchase) requires the active participation of the three main parties, and optimization and adjustment from the overall perspective; (no incentive, development, purchase) is the scenario of less government intervention, which is the mature stage of sponge project development.

Second, the important factors affecting the decision direction of the game players are direct cost, direct benefit, opportunity cost, and opportunity benefit. Changing the initial value of the parameters will affect the evolution speed of the decision when the decision direction is unchanged. Under the oversupply scenario and short supply scenario, the whole evolution speed can be reduced by changing a few related parameters, thereby reducing the loss in time, and the incentive and construction scheme can be improved after the buffer time. In the scenario of supply and demand coordination, the total income of the three parties is higher than the total cost. Adjusting the parameters can accelerate the overall evolution speed, thereby quickly promote the construction and development of sponge city.

Third, the construction and development of sponge city need the joint efforts of the government, developers, and consumers. The government's incentive measures act directly on developers and consumers, which can directly affect developers' development motivation and consumers' purchase desire. However, when the development cost and acquisition cost are high, the government's incentive cost will be too high in order to mobilize the construction enthusiasm of the other two groups. Therefore, the government should consider cost control and improve research development incentive to solve the problem of high cost. The government should focus on guidance, not pass construction risks to developers, but encourage healthy competition among developers, not force consumers to bear construction costs, and increase consumers' attention and participation in sponge cities. Developers should make long-term planning, actively understand the market situation, learn advanced technology, keep pace with the times, and develop together with the market. After the developer's construction ratio exceeds the equilibrium point, consumer purchase trends will decline. On the one hand, it is necessary to reasonably adjust the developer's construction equilibrium point so that it cannot be too small; on the other hand, it is necessary to consider the matching between supply speed and 
demand speed. The oversupply situation is also not conducive to the long-term development of the sponge project. In order to respond to the requirements of the overall construction of the sponge city, developers need to design and create different products for consumers with different consumption levels. Products for conservative consumers must ensure that they meet government standards, control costs, and ensure quality. For general consumption, developers can design products with certain characteristics, give attention to both beautiful and practical. For consumers seeking quality, developers can use comprehensive advanced technology to create high-quality products. Consumers should actively respond to the government's call, establish a sense of ownership, and take the initiative to understand relevant knowledge and information. The public should improve their willingness to participate, and consumer demand is the starting point of developers' construction. They should supervise the construction quality spontaneously, improve the construction requirements, care about the progress of the project, put forward problems on the demand side and reasonable suggestions, promote the high-quality construction of sponge project, and promote the creation of beautiful urban and rural areas.

The first innovation of this paper is the research perspective. In the previous game study on sponge city construction, only two stakeholders were considered. In this paper, consumers were added as stakeholders and an evolutionary game from the perspective of three parties was tried. Second, the research object is no longer limited to non-profit projects, and the projects with their own profitability are easier to be promoted. The third is the research approach. This article uses evolutionary game method to study and analyze different scenarios of sponge city construction and development.

In this paper, the model of sponge city promotion phase is established, the stakeholder selection strategy is relatively simple, the parameter setting is relatively simplified, and the influence of disturbance factors on the decision-making direction is studied. In the next phase of relevant research, we intend to analyze the problems in the development stage of sponge cities and explore the influence of government incentive ratio, developer construction quality, and consumer maintenance efficiency on the overall development of sponge cities.

Author Contributions: Conceptualization, Y.C.; methodology, Y.C. and H.C.; validation, Y.C. and H.C.; investigation, Y.C and H.C.; writing-original draft preparation, Y.C and H.C.; writing-review and editing, Y.C. and H.C.; visualization, H.C.; funding acquisition, Y.C. All authors have read and agreed to the published version of the manuscript.

Funding: This work was supported by National Natural Foundation for young scholar (grant No. 71403122), Natural Foundation of Jiangsu Province for young scholar (grant No. BK20140980), and Humanities and Social Science Foundation of Chinese Ministry of Education for young scholar (grant No. 14YJC630018).

Conflicts of Interest: The authors declare no conflict of interest.

\section{References}

1. Xiang, X. Study on Performance Appraisal of PPP Project in Sponge City. Master's Thesis, Beijing University of Civil Engineering and Architecture, Beijing, China, 2019.

2. Wang, Y.; Sun, M.; Song, B. Public perceptions of and willingness to pay for sponge city initiatives in China. Resour. Conserv. Recycl. 2017, 122, 11-20. [CrossRef]

3. Jia, H.; Yao, H.; Tang, Y.; Shaw, L.Y.; Field, R.; Tafuri, A.N. LID-BMPs planning for urban runoff control and the case study in China. J. Environ. Manag. 2015, 149, 65-76. [CrossRef] [PubMed]

4. Dietz, M.E.; Clausen, J.C. Stormwater runoff and export changes with development in a traditional and low impact subdivision. J. Environ. Manag. 2008, 87, 560-566. [CrossRef] [PubMed]

5. Coombes, P.J.; Argue, J.R. Figtree Place: A case study in water sensitive urban development (WSUD). Urban Water 2000, 1, 335-343. [CrossRef]

6. Jefferies, C.; Duffy, A.; Berwick, N. Sustainable Urban Drainage Systems (SUDS) treatment train assessment tool. Water Sci. Technol. 2009, 60, 1233-1240. [CrossRef]

7. Li, H.; Ding, L.; Ren, M.; Li, C.; Wang, H. Sponge City Construction in China: A Survey of the Challenges and Opportunities. Water 2017, 9, 594. [CrossRef] 
8. The Telegraph News. Available online: http:/www.telegraph.co.uk/news/world/china-watch/business/ china-flooding-sponge-city/ (accessed on 26 March 2020).

9. Che, W.; Lv, F.F.; Li, J.Q. Typical Stormwater and Flood Management Systems in Developed Countries and Their Inspiration. China Water Wastewater 2009, 20, 12-17.

10. Zhang, W.; Che, W.; Wang, J. Management of urban stormwater runoff by green Infrastructures. China Water Wastewater 2011, 27, 22-27.

11. Che, W.; Ma, Z. Specific planning for stormwater management and utilization in Chinese urban planning system. China Water Wastewater 2013, 29, 8-12.

12. Ministry of Housing and Urban-Rural Development of People's Republic of China. Technical Guide for Sponge City Construction: Construction of Rainwater System for Low-Impact Development (Trial). Available online: http://www.ccement.com/news/content/8039753005032.html (accessed on 22 December 2019).

13. Xia, J.; Zhang, Y. Opportunities and challenges of the Sponge City construction related to urban water issues in China. Sci. China Earth Sci. 2017, 60, 652-658. [CrossRef]

14. Zhou, L. Reflections on the preparation of planning and design guidelines of sponge city in Zhejiang Province. City Plann. Rev. 2018, 42, 111-116.

15. Hu, Q.; Liu, C. Cost-benefit analysis of green renovation of existing residential areas in sponge city construction. J. Tianjin Chengjian Univ. 2018, 24, 448-453.

16. Shi, H.; Lin, Z. “The Supreme Virtue Is Like Water" Ecological Landscape Design of Kunshan Duke University. Archit. J. 2018, 3, 94-100.

17. Han, X.; $\mathrm{Wu}, \mathrm{Y}$. Construction and Application of "the Sponge City" in Different Precipitation Regions: Case Studies in Pingxiang and Ji'nan, China. Energy Procedia 2019, 159, 207-212. [CrossRef]

18. Tang, P.; Wang, H. Quantitative research on rain-flood patterns of urban area in the construction of "Sponge Cities". J. Nanjing For. Univ. 2018, 42, 15-20.

19. Li, Q.; Wang, F.; Yu, Y. Comprehensive performance evaluation of LID practices for the sponge city construction: A case study in Guangxi, China. J. Environ. Manag. 2019, 231, 10-20. [CrossRef]

20. Pang, X.; Zhang, Y.; Pan, X. Urban stormwater simulation and assessment of the control rate of total annual runoff: A case of the Future Science and Technology Park in Beijing. Resour. Sci. 2019, 41, 803-813. [CrossRef]

21. Randall, M.; Sun, F.; Zhang, Y. Evaluating Sponge City volume capture ratio at the catchment scale using SWMM. J. Environ. Manag. 2019, 246, 745-757. [CrossRef]

22. Xiang, P.; Jia, F. Risk assessment method of sponge city construction under grey intuitionistic fuzzy analytic hierarchy process. Sci. Technol. Manag. Res. 2018, 38, 113-119.

23. Dai, Y.; Jiao, S. Review and prospect of sponge city construction in recent ten years. Mod. Urban Res. 2018, 8 , 77-87.

24. Liu, L.; Jensen, M.B. Green infrastructure for sustainable urban water management: Practices of five forerunner cities. Cities 2018, 74, 126-133. [CrossRef]

25. Xu, T.; Li, K.; Engel, B.A. Optimal adaptation pathway for sustainable low impact development planning under deep uncertainty of climate change: A greedy strategy. J. Environ. Manag. 2019, 248, 109280. [CrossRef] [PubMed]

26. He, B.J.; Zhu, J.; Zhao, D.X.; Gou, Z.H. Co-benefits approach: Opportunities for implementing sponge city and urban heat island mitigation. Land Use Policy 2019, 86, 147-157. [CrossRef]

27. Qiao, X.J.; Liu, L.; Kristoffersson, A. Governance factors of sustainable stormwater management: A study of case cities in China and Sweden. J. Environ. Manag. 2019, 248, 109249. [CrossRef]

28. Wang, S.; Hao, Y. A risk dynamic evaluation of PPP projects in sponge city based on system dynamics. J. Eng. Manag. 2019, 33, 63-68. [CrossRef]

29. Cui, F.; Tu, R.; Wang, X. Summarizing and thinking on the periodic problem of sponge city construction. China Popul. Resour. Environ. 2018, 28, 33-36.

30. Yang, J.; Ye, J.; Wang, H. Study on Stakeholder Game in the Ecological Civilization Construction. For. Econ. 2018, 40, 9-14,19.

31. Liang, X. Integrated Economic and Financial Analysis of China's Sponge City Program for Water-resilient Urban Development. Sustainability 2018, 10, 669. [CrossRef]

32. Yin, S.; Li, B.; Xing, Z. The governance mechanism of the building material industry (BMI) in transformation to green BMI: The perspective of green building. Sci. Total Environ. 2019, 677, 19-33. [CrossRef] 
33. Li, Q.; Bao, H.; Peng, Y.; Wang, H. The collective strategies of major stakeholders in land expropriation: A tripartite game analysis of central government, local governments, and land-lost farmers. Sustainability 2017, 9, 648. [CrossRef]

34. Du, Y.; Zhou, H.; Yuan, Y.; Xue, H. Exploring the Moral Hazard Evolutionary Mechanism for BIM Implementation in an Integrated Project Team. Sustainability 2019, 11, 5719. [CrossRef]

35. Li, K.; Wang, W.; Zhang, Y. Game Modelling and Strategy Research on the System Dynamics-based Quadruplicate Evolution for High-speed Railway Operational Safety Supervision System. Sustainability 2019, 11, 1300. [CrossRef]

36. Chen, Y.; Zhu, D.; Zhou, L. A game theory analysis of promoting the spongy city construction at the building and community scale. Habitat Int. 2019, 86, 91-100. [CrossRef]

37. Li, Q.; Long, R.; Chen, H.; Chen, F.; Cheng, X. Chinese urban resident willingness to pay for green housing based on double-entry mental accounting theory. Nat. Hazards 2019, 95, 129-153. [CrossRef]

(C) 2020 by the authors. Licensee MDPI, Basel, Switzerland. This article is an open access article distributed under the terms and conditions of the Creative Commons Attribution (CC BY) license (http://creativecommons.org/licenses/by/4.0/). 